\title{
Level of Self-care Practice and Associated Factors Among Hypertensive Patients in Jimma University Specialized Hospital, South West Ethiopia
}

\author{
Anwar Abdulwahed ${ }^{1, ~ *, ~ A n w a r ~ S e i d ~}{ }^{2}$ \\ ${ }^{1}$ College of Health Science, Arsi University, Asella, Ethiopia \\ ${ }^{2}$ College of Health Science, Samara University, Semera, Ethiopia
}

Email address:

anwarsheca@gmail.com (A. Abdulwahed)

${ }^{*}$ Corresponding author

To cite this article:

Anwar Abdulwahed, Anwar Seid. Level of Self-care Practice and Associated Factors Among Hypertensive Patients in Jimma University Specialized Hospital, South West Ethiopia. Rehabilitation Science. Vol. 5, No. 2, 2020, pp. 12-17.

doi: $10.11648 /$ j.rs.20200502.11

Received: February 24, 2020; Accepted: August 31, 2020; Published: September 17, 2020

\begin{abstract}
Globally hypertension is a major public health problem and leading cause of mortality in developing countries. Self-care practice encourage hypertensive patients to have better quality of life by preventing complication and decrease health care expenditure. The aim of this study is to assess Self-care practice and associated factors among hypertension patients in Jimma university specialized hospital, south west Ethiopia. An institution based Cross sectional study was employed on 322 adult hypertensive patients using simple random sampling procedure between March to May, 2016. Data was analyzed using SPSS version 20.0. A p-value of $<0.05$ was considered as statistically significant. Adjusted odds ratio at $95 \%$ CI was considered to declare the independent effect of independents variables on the outcome. In this study, the overall participants with the recommended level of self-care practice were found to be $44.7 \%$. Being employed [AOR $=2.032,95 \%$ Confidence Interval $[\mathrm{CI}]:(1.162,3.552)$, educational attainment $(\mathrm{AOR}=3.730,95 \% \mathrm{CI}:(1.837,7.576)$ and Presence of co morbidity diseases $(\mathrm{AOR}=0.502,95 \% \mathrm{CI}: 0.2886,0.8850)$ were factors significantly associated with self-care practice. This study revealed level of self-care practice were low among hypertensive patients. Occupation, educational status and comorbidity were factors significantly associated with Self-care practice. Hypertensive patients with low socioeconomic status, no formal educational attainment and with co-morbidity needs special attention to improve their self-care practice.
\end{abstract}

Keywords: Hypertension, Self-care, Practice, Jimma

\section{Introduction}

Worldwide, hypertension is common and now regarded as a major public health problem [1]. It is an overwhelming global challenge and analysis of the global burden of hypertension revealed that over $25 \%$ of the world's adult population had hypertension in 2000 , and the proportion is expected to increase to $29 \%$ by 2025 [2]. Hypertension is usually a chronic disease which can lead to long term complications and it is the leading cause of death and the second leading cause of lost disability adjusted life-years worldwide [3].

Hypertension is a leading cause of death in developing countries. According to the World Health Organization, more than $80 \%$ of deaths from hypertension and associated cardiovascular diseases now occur in low and middle-income countries and this is particularly common among people of low socio-economic status [4].

Based on world health organization (WHO), one method to control hypertension is to involve patients in their own selfcare practice $[5,6]$. Self-care practice encourage patients with variety of illness to have better quality of life by preventing complication and decrease health care expenditure. It has shown that it reduces primary care visits or outpatient visits by $17 \%$ and emergency department visits up to $50 \%$ [7].

Different finding encourage compliance with hypertension self-care practice such as weight reduction, smoking cessation, low salt diet, and physical activity can contribute 
to controlling blood pressure [8, 9]. A clinic based study in rural area of Singur, West Bengal revealed that primary level education, poor socio economic status, widow/separated and people with self-perceived poor health status had significant association with unfavorable self-care practices [10].

Another study in Saudi Arabia showed that awareness, Knowledge and self-management practices were found to be significantly poor among old age groups (above 50 years), males and less educated patients [11].

Although different treatment option present to manage hypertension, hypertension control is still poor, with less controlled blood pressure witnessed. Hypertension selfmanagement behaviors comprising medication adherence, selfblood pressure monitoring, and lifestyle modifications involving diet, exercise, and tobacco are critical components of recommended hypertension treatment and have been associated with significant improvements in hypertension control [12].

Most of the studies conducted identifies medication adherence alone, but limited study on importance of self-care that is essential in controlling hypertension. Considering this current study aims to assess level of self-care practice and the factors associated among hypertensive patients in Jimma University Specialized Hospital, South West Ethiopia, 2016.

\section{Methods}

\subsection{Study Design, Period and Setting}

An institution based cross sectional study was conducted between March to May, 2016. The study was conducted in Jimma University Specialized Hospital which is found in Jimma town, Ethiopia. As one of the outpatient services, the hospital has specialty clinics where patients with specific chronic disease are referred for follow-up. Hypertension clinic is one of those clinics which give service for patients with hypertension disorder.

\subsection{Study Population, Sample Size and Sampling Procedure}

The study population were hypertensive patients whose aged greater than 18 years and put on treatment for at least 3 months in hypertension clinic of Jimma University Specialized Hospital.

The sample size was determined using a single population proportion formula by assuming that $50 \%$ proportion of the patients practiced self-care practice with $95 \%$ confidence interval and 5\% margin of error. Using population correction formula because the source population is less ten thousand and adding 10\% non-response rate the sample size was 322 .

The study participants were selected using simple random sampling technique by considering the total adult hypertensive follow-up patients which are 1342 in Jimma University Specialized Hospital as sampling frame. First of all the list of patients was obtained from the registration books of the patients registered for follow up in hospitals and study subjects were selected by lottery method.

\subsection{Data Collection Tools}

Data were collected using structured questionnaire prepared in local language after reviewing different literatures. The questionnaire covered a range of topics including sociodemographic factors and self-care practice question. Level of self-care practice was assessed by 12 questions which were adapted from Hypertension self-care activity level effects (H-SCALE), which is a self-report assessment designed to measure the self-care activities recommended by Joint National committee-7 (JNC 7) [[13]]. Level of self-care practice was classified as a 'good practice' and 'poor practice'. Respondents were labeled to have "good" "self-care practice if they scored above the mean in all recommended self-care questions.

\subsection{Data Collectors and Quality Control}

The data was collected by five nurses working in Jimma University Specialized Hospital other than chronic illness department through face to face interview and record review. A training of 2 days was given to recruited data collectors and supervisors. The training mainly focused on equipping the trainees with information about the objective of the study, techniques of interview, collection of data, and relevant ethical issues. The data collection tool was pretested on $5 \%$ of the study subjects in other hospitals. During the pre-test, the acceptability and applicability of the procedures and tools were evaluated. All questioners were regularly checked for completeness, clarity, and consistency by the respective supervisors.

\subsection{Data Processing and Analysis}

Data was edited and entered using Epidata 3.1 version then exported to SPSS version 20 for analysis. Frequency distribution was used to organize the data and present the responses obtained. Moreover bivariate logistic regression was done to examine the association between dependent and independent variables. After running bivariate logistic regressions, all variables with $\mathrm{p}<0.25$ was considered as a candidate for the final model and corresponding p-value of $<0.05$ was considered as statistically significant. Adjusted odds ratio at $95 \% \mathrm{CI}$ was considered to declare the independent effect of independents variables on the outcome. Finally, results were presented using charts and tables.

\subsection{Ethical Standards Disclosure}

The study was reviewed and approved by Jimma University, College of Health and Medical Sciences, Institutional Health Research Ethical Review Committee. Written consent was obtained from each patient before initiation of data collection. To maintain confidentiality of information names and other identifiers were not used in the questionnaire

\section{Results and Discussion}

From a total sample 322 participants were interviewed yielding $98 \%$ response rate. More than half were in age 
group 41-60 year 171 (53.1\%), male $176(54.7 \%)$ and Muslim 183 (56.8). About two-third were Oromo in ethnicity
$214(66.5 \%)$. Regarding the educational status those who can read and write accounts about 248 (77\%). (Table 1)

Table 1. Socio demographic characteristic of hypertensive patients in Jimma University Specialized Hospital, March to April 2016 ( $n=322$ ).

\begin{tabular}{|c|c|c|c|}
\hline \multirow{2}{*}{ Variable } & \multirow{2}{*}{ Profile } & \multicolumn{2}{|c|}{ Frequency } \\
\hline & & $\mathbf{N}$ & $\%$ \\
\hline \multirow{3}{*}{ Age } & $18-40$ years & 69 & 21.4 \\
\hline & $41-60$ years & 171 & 53.1 \\
\hline & $>=60$ years & 82 & 25.5 \\
\hline \multirow{2}{*}{ Sex } & Male & 176 & 54.7 \\
\hline & Female & 146 & 45.3 \\
\hline \multirow{3}{*}{ Religion } & Orthodox & 120 & 37.3 \\
\hline & Protestant & 15 & 4.7 \\
\hline & Other & 4 & 1.2 \\
\hline \multirow{4}{*}{ Ethnicity } & Oromo & 214 & 66.5 \\
\hline & Amhara & 49 & 15.2 \\
\hline & Dawuro & 28 & 8.7 \\
\hline & Others & 10 & 3.1 \\
\hline \multirow{2}{*}{ Marital status } & Married & 284 & 88.2 \\
\hline & Single/widowed/divorced & 38 & 11.8 \\
\hline \multirow{2}{*}{ Education } & Cannot read and write & 74 & 23 \\
\hline & Can read and write & 248 & 77 \\
\hline \multirow{2}{*}{ Occupation } & Unemployed & 183 & 56.8 \\
\hline & Employed & 139 & 43.2 \\
\hline \multirow{2}{*}{ Monthly income (in Birr) } & $<1000$ & 191 & 59.3 \\
\hline & $>=1000$ & 131 & 40.7 \\
\hline
\end{tabular}

\subsection{Level of Self-care Practice Among Hypertensives Patients}

In this study only $44.7 \%$ hypertensive patients had good self-care practice to control their blood pressure. Of the study participant involved in this study about $40.4 \%$ of patients were taking their medication regularly. (Table 2 ).

Table 2. Distribution of hypertensive patients about habit of doing self-care practice in Jimma University Specialized Hospital, March to April 2016 (n=322).

\begin{tabular}{|c|c|c|c|c|}
\hline \multirow{2}{*}{\multicolumn{2}{|c|}{ Self-care practices question }} & \multirow{2}{*}{ Responses } & \multicolumn{2}{|c|}{ Frequency } \\
\hline & & & $\mathbf{N}$ & $\%$ \\
\hline \multirow{2}{*}{\multicolumn{2}{|c|}{ Taking Medication regularly }} & yes & 130 & 40.4 \\
\hline & & No & 192 & 59.6 \\
\hline \multirow{2}{*}{\multicolumn{2}{|c|}{ Smoking }} & Yes & 9 & 2.8 \\
\hline & & No & 313 & 97.2 \\
\hline \multirow{2}{*}{\multicolumn{2}{|c|}{ Alcohol drinking }} & Yes & 15 & 4.7 \\
\hline & & No & 307 & 95.3 \\
\hline \multirow{8}{*}{ Dietary habit } & \multirow{2}{*}{ Fat meal intake } & Yes & 59 & 18.3 \\
\hline & & No & 263 & 81.7 \\
\hline & \multirow{2}{*}{ Fast food intake } & Yes & 153 & 47.5 \\
\hline & & No & 169 & 52.5 \\
\hline & \multirow{2}{*}{ Salt diet intake } & Yes & 95 & 29.5 \\
\hline & & No & 227 & 70.5 \\
\hline & \multirow{2}{*}{ Vegetables intake } & Yes & 107 & 33.2 \\
\hline & & No & 215 & 66.8 \\
\hline \multirow{2}{*}{\multicolumn{2}{|c|}{ Monitoring blood pressure }} & Yes & 80 & 24.8 \\
\hline & & No & 242 & 75.2 \\
\hline \multirow{2}{*}{\multicolumn{2}{|c|}{ Physical exercise }} & Yes & 247 & 76.7 \\
\hline & & No & 75 & 23.3 \\
\hline \multirow{2}{*}{\multicolumn{2}{|c|}{ Try to have weight loss }} & Yes & 263 & 81.7 \\
\hline & & No & 59 & 18.3 \\
\hline \multirow{2}{*}{\multicolumn{2}{|c|}{ Using Measure to reduce stress }} & Yes & 191 & 59.3 \\
\hline & & No & 131 & 40.7 \\
\hline \multirow{2}{*}{\multicolumn{2}{|c|}{ Have enough sleep }} & Yes & 75 & 23.3 \\
\hline & & No & 247 & 76.7 \\
\hline \multirow{2}{*}{\multicolumn{2}{|c|}{ Over all self-care practice }} & Good & 144 & 44.7 \\
\hline & & Poor & 178 & 55.3 \\
\hline
\end{tabular}




\subsection{Factors Associated with Self-care Practice Among Hypertensive Patients}

Logistic Regression was used aiming at identifying associated factors of self-care practice. Age, sex, marital status, occupation, educational status, monthly income, duration of illness, BMI, co-morbidity status and history of medication side effects were entered into the final model. According to the result of the multivariable analysis occupation, educational status and co-morbidity were independent factors of self-care practice among hypertensive patients.
Employed patients were 2.03 more likely to have good self-care practice $(\mathrm{AOR}=2.03,95 \% \mathrm{CI}: 1.16,3.55)$ than unemployed patients. On the other hand, hypertensive patients who can read and write were 3.73 times more likely to practice good self-care activities $(\mathrm{AOR}=3.73,95 \% \mathrm{CI}$ : $1.84,7.57$ ) as compared to those who were not able to read and write. Patients with co-morbidity were $50 \%$ less likely to practice self-care activities (AOR $=0.5,95 \% \mathrm{CI}: 0.29,0.88)$ as compared to those without co-morbidity. (Table 3 ).

Table 3. Factors affecting level of self-care practice among hypertensive patients in Jimma University Specialized Hospital, March to April 2016 ( $n=322$ ).

\begin{tabular}{|c|c|c|c|c|}
\hline \multirow{2}{*}{ Variable } & \multicolumn{2}{|c|}{ Self care practice } & \multirow{2}{*}{ Crude OR (95\% CI) } & \multirow{2}{*}{ Adjusted OR (95\% CI) } \\
\hline & Good & Poor & & \\
\hline \multicolumn{5}{|l|}{ Sex } \\
\hline Male & 79 & 97 & $1.015(0.653,1.578)$ & $0.661(0.375,1.166)$ \\
\hline Female & 65 & 81 & 1 & 1 \\
\hline \multicolumn{5}{|l|}{ Age } \\
\hline $18-40$ & 37 & 32 & 1 & 1 \\
\hline $41-60$ & 66 & 105 & $0.544(0.309,0.956)$ & $0.550(0.289,1.046)$ \\
\hline$>=60$ & 41 & 41 & $0.865(0.455,1.642)$ & $1.437(0.659,3.131)$ \\
\hline \multicolumn{5}{|l|}{ Marital status } \\
\hline Married & 128 & 156 & $1.128(0.569,2.238)$ & $0.862(0.388,1.913)$ \\
\hline Single/separated & 16 & 22 & 1 & 1 \\
\hline \multicolumn{5}{|l|}{ Occupation } \\
\hline Unemployed & 62 & 121 & 1 & 1 \\
\hline Employed & 82 & 57 & $2.808(1.779,4.430)$ & $2.032(1.162,3.552)^{*}$ \\
\hline \multicolumn{5}{|l|}{ Educational status } \\
\hline Illiterate & 17 & 57 & 1 & 1 \\
\hline Literate & 127 & 121 & $3.519(1.939,6.388)$ & $3.730(1.837,7.576)^{*}$ \\
\hline \multicolumn{5}{|l|}{ Monthly income } \\
\hline$<1000$ & 74 & 117 & 1 & 1 \\
\hline$>=1000$ & 70 & 61 & $1.814(1.157,2.846)$ & $1.271(0.729,2.217)$ \\
\hline \multicolumn{5}{|l|}{ Duration of illness } \\
\hline$<5$ years & 102 & 115 & 1 & 1 \\
\hline$>=5$ years & 42 & 63 & $1.330(0.829,2.135)$ & $0.659(0.386,1.126)$ \\
\hline \multicolumn{5}{|l|}{ Body Mass Index } \\
\hline$<18$ & 11 & 8 & 1 & 1 \\
\hline $18-24.99$ & 102 & 126 & $0.589(0.228,1.518)$ & $0.528(0.187,1.489)$ \\
\hline $25-29.99$ & 26 & 39 & $0.485(0.172,1.368)$ & $0.492(0.157,1.540)$ \\
\hline$>=30$ & 5 & 5 & $0.727(0.156,3.386)$ & $0.549(0.102,2.952)$ \\
\hline \multicolumn{5}{|l|}{ Co-morbidity } \\
\hline Yes & 46 & 86 & $0.502(0.31,0.793)$ & $0.503(0.2886,0.885)^{*}$ \\
\hline No & 98 & 92 & 1 & 1 \\
\hline \multicolumn{5}{|c|}{ History of medication side effects } \\
\hline Yes & 17 & 35 & $0.547(0.292,1.024)$ & $0.682(0.333,1.397)$ \\
\hline No & 127 & 143 & 1 & 1 \\
\hline
\end{tabular}

${ }^{*}$ p-value $<0.05$

The current study was undertaken to highlight the level of self-care practice and associated factors among hypertensive population. In this study $46.7 \%$ of the participants had good self-care practice. This figure is high when compared to study conducted in Durame and Nigist Elleni Mohamed Memorial General Hospitals, SNNPR, Ethiopia which was $27.3 \%$ [14] and this difference may be due to educational back ground of patients and level of awareness about benefits of self-care practice. Another study conducted in North Carolina revealed similar prevalence rates of recommended hypertension self-care activities were greater than $50 \%$ for behaviors related to medication adherence, physical activity, not smoking, and alcohol abstinence [15]. In contrary to this finding another study conducted in Mumbai shows a high proportion of unfavorable self-practice, as it is conducted in a slum [16] this difference might be due to cultural and 
geographical variation.

Results from multiple logistic regression analysis showed that occupational status, educational status, and co morbidity were significantly associated with self-care practice. The results of the analysis showed employed patients was 2.03 more likely to practice self-care activities compared to unemployed and this finding is comparable with another study conducted in West Bengali with (OR-2.4). This could be due to individuals who have no occupation could face to manage their self-care activities properly and could not get favorable setups to do physical exercise.

Regarding educational status those Patients who can read and write was 3.7 more likely to practice self-care activities compared to those who are unable to read and write and this finding is similar with study conducted in West Bengal and in Saudi Arabia found that self-management practices were significantly poor among less educated $[11,14]$. This might be individuals who have better level of education know more about self-care management activities.

In this study patient with co-morbidity was 50\% less likely to practice self-care activities $(\mathrm{AOR}=0.5,95 \% \mathrm{CI}: 0.2886$, 0.885 ) compared to patients without comorbidity and this is in line with study conducted in south Ethiopia and Addis Ababa Black Lion Hospital [14, 17]. This might be comorbidities can worsen the conditions of the patient and make them unable to adhere to self-care activities.

\section{Conclusion}

This study revealed level of self-care practice is below average among the hypertensive patients. Occupation, educational status, and comorbidity were factors significantly associated with level of self-care practice. Hypertensive patients with low socioeconomic status, no formal educational attainment and with co-morbidity needs special attention to improve their self-care practice in order to control high blood pressure.

\section{Acknowledgements}

The authors would like to acknowledge the Federal Minister of Education of Ethiopia and Jimma University for their financial support for this research. The authors are very much grateful to the study participants and data collectors.

\section{Author Contributions}

Anwar Abdulwahed conceived and designed the study, interpreted the data and drafted the manuscript. Anwar Seid helped in literature searches, provided critical review and comments on the manuscript. All authors contributed toward data analysis and critically revising the paper.

\section{Disclosure}

The authors declare that they have no conflicts of interest.

\section{References}

[1] Cappuccio FP, Micah FB, Emmett L, Kerry SM, Antwi S, Martin-peprah R, et al. Prevalence, Detection, Management, and Control of Hypertension in Ashanti, West Africa. American Heart Association Journal. 2004; 1017-22.

[2] Hareri HA, Abebe M. Assessments of Adherence to Hypertension Medications and Associated Factors among Patients Attending Tikur Anbessa Specialized Hospital Renal Unit, Addis Ababa, Ethiopia 2012. Inter. Journal of Nursing Science 2013; 3 (1): 1-6.

[3] Quang, Nguyen., Joann Dominguez., Loida Nguyen. \& GN. Hypertension management: An update. American Health and Drug Benefits. 2010; 3 (1): 47.

[4] Abdesslam, Boutayeband Saber Boutayeb the burden of noncommunicable diseases in developing countries, International Journal Equity Health. 2005; 4 (2).

[5] Chobanian AV, Bakris GL, Black HR, Cushman WC, Green LA, Izzo JJ et al. The Seventh Report of the Joint National Committee on Prevention, Detection, Evaluation, and Treatment of High Blood Pressure: the JNC 7 report. JAMA. 2003; 289 (19): 2560-72. Doi: 10.1001/jama.289.19.2560. [PubMed: 12748199].

[6] Yang SO, Jeong GH, Kim SJ, Lee SH. Correlates of self-care behaviors among low-income elderly women with hypertension in South Korea. J ObstetGynecol Neonatal Nurs. 2014; 43 (1): 97-106. Doi: 10.1111/1552-6909.12265. [PubMed: 24354464].

[7] Department of Health, NHS. Supporting people with long term conditions to Self-care. A guide to developing local strategies and good practice. 2006.

[8] Logan, A. G., et al., Effect of home blood pressure tele monitoring with self-care support on uncontrolled systolic hypertension in diabetics. Hypertension AHA journals.org, 2012. 60: p. 51-57.

[9] Yeon-Hwan Park et al., The effect of an integrated health education and exercise program in community- dwelling older adults with hypertension: a randomized controlled trial. Patient Education and Counseling, 2011. 82: p. 133-137.

[10] Aparajita Dasgupta, Sembagamuthu Sembiah, Bobby Paul, Ayon Ghosh, Bijit Biswas, Nazrul Mallick, Assessment of self-care practices among hypertensive patients: a clinic based study in rural area of Singur, West Bengal, 30 November 2017.

[11] Bakhsh LA, Adas AA, Murad MA, Nourah RM, Hanbazazah SA, Aljahdali AA, Alshareef RJ. Awareness and Knowledge on Hypertension and its Self- Care Practices among Hypertensive Patients in Saudi Arabia. Ann. Int. Med. Den. Res. 2017; 3 (5): ME58-ME62.

[12] Giles T, Aranda JM, Jr, Suh DC, et al. Ethnic/racial variations in blood pressure awareness, treatment, and control. Journal of Clinical Hypertension (Greenwich) 2007; 9 (5): 345-354. [PubMed].

[13] Warren-Findlow J, Basalik DW, Dulin M, Tapp H, Kuhn L. Preliminary validation of the Hypertension Self-Care Activity Level Effects (H-SCALE) and clinical blood pressure among patients with hypertension. Journal Clinical Hypertension 2013; 15 (9): 637-43. 
[14] Eyasu Siyum Buda, Lolemo Kelbiso Hanfore, Lifestyle modification practice and associated factors among diagnosed hypertensive patients in selected hospitals, South Ethiopia.

[15] Dr Jan Warren-Findlow, Prevalence Rates of Hypertension Self-care Activities among African Americans, J Natl Med Assoc. 2011 June; 103 (6): 503-512.

[16] Mahajan H, Kazi Y, Sharma B, Velhal GD. Assessment of KAP, Risk Factors and Associated Co-Morbidities in
Hypertensive Patients. Journal of Dental Med Sci. 2012; 1 (2): 06-14.

[17] Hareri HA, Abebe M, Asefaw T. Assessments of adherence to hypertension managements and its influencing factors among hypertensive patients attending black lion hospital chronic follow up unit, Addis Ababa, Ethiopia-a cross-sectional study. International Journal of Pharmaceutical Science Research, 2013; 4 (3): 1086-95. 